\begin{tabular}{|c|c|}
\hline & Volume \& Issues Obtainable at The Women University Multan \\
& Annals of Social Sciences and Perspective \\
& ISSN: 2707-7063, Volume 1, No.2 December 2020 \\
\hline
\end{tabular}

\title{
Impact of COVID-19 on Vulnerable Groups: A Need for Mental Health Facilities
}

\section{Ruqia Safdar Bajwa ${ }^{1}$}

The latest challenge for the universe is Novel Coronavirus disease 2019 (COVID-2019). Although it is not new for the entire medical world this recent outbreak is new in humans. It started in Wuhan, China through animal to human spread but later on it was evidenced as human to human spread. On January 30, WHO declared Public health emergency around the world but did not impose trade and travel restrictions. Following China, On 19 February Iran spoke about 2 deaths due to COVID-19. Pakistan shares its border with China and Iran and has trade and travel relations with both countries. So this virus was imported through travelers and 1st case was reported on 26 February in Pakistan (Health, 2020). Until today number of cases has been outstretched up to 28,736 while 636 deaths were reported (Worldometer, 2020). All these current scenarios, call for attention to the impact of this pandemic on mental health. When large numbers of people get sick or die as a result of epidemics or pandemics, it leads to greater risks for psychosocial problems. History reminds us that SARS was the $1^{\text {st }}$ hard hit of the $21^{\text {st }}$ Century and researchers reported the huge psychosocial impact of SARS upon people (Sim \& Chua, 2004). A study by Nickell and colleagues elaborated on this impact and contributed towards the knowledge by carrying out the study in a Canada based teaching hospital during 2003 when the outbreak was at the peak. Emotional distress, psychiatric comorbidity, huge concerns for personal and family health were reported by the participants (Nickell et al., 2004). The substantial rise in anxiety is associated with deaths, news and quarantine (Lima et al., 2020).

A recent study conducted in mainland China reported about the very initial stage of the outbreak, the psychological impact was reported from moderate to severe. The participant had moderate to severe depressive and anxiety symptoms as well as heightened stress levels (Wang et al., 2020). Another major concern is related to quarantine, it is heavily impacting mental health as well as provoking discrimination and potential anger (Brooks et al., 2020).

An immediate need for mental health care emerges and requires the identification of vulnerable groups and the provision of immediate help to them. Vulnerability is an internal state of the individual that makes them sensitive due to the interaction of different factors. Common vulnerable groups are children, adolescents, elderly, women, minority groups, marginalized people, people with disabilities and people with a history of illness with physical or psychological (PAHO, 2005). During the current situational framework, patients, their families as well as front-line healthcare personnel are vulnerable to the huge emotional impact of novel coronavirus (Folkman \& Greer, 2000; Harley \& Maunder, 2003; Zhou et al., 2020). This contagious epidemic has accentuated potential cavities in mental health service areas during emergencies (Lima et al., 2020). Roughly 50 percent of individuals from developed countries and 85 percent from the developing world have mental health issues (Pescosolido \&

\footnotetext{
${ }^{1}$ PhD Scholar, Universiti Putra Malaysia.
} 
Olafsdottir, 2013) but this problem is more severe in middle and low income countries and 80 percent of the total mental health patients belong to these countries (Thyloth, Singh, \& Subramanian, 2016). Mental illness in Pakistan is widely ignored; misinterpreted mismanaged (Shah, 2019) and mental health services are rare. In Pakistan 10-16 percent, people suffer from moderate mental problems and 1 percent suffered from severe mental health issues (Gadit, 2007) thus highlights them as a potentially vulnerable group. The cause of this worrisome number of patients is mix fold owing to severe sociocultural and economic reasons. During the last 2 decades the security situation of the country was much unstable and war on terror and many other factors gave rise to mental health problems (Husain, Chaudhry, Afridi, Tomenson, \& Creed, 2007). So, Pakistan authorities must take immediate action to safeguard this vulnerable group by making policies according to the SOPs of WHO. Online mental health services should be provided and psychologists around the country must be taken on board along with the doctors and other health care staff. Pakistan can take guidelines from The National Health Commission in China, they published detailed guidelines since the begging of coronavirus in china, these guidelines include notification of moralities for emergency intervention during psychological crisis and notices about hotlines regarding psychological assistance during epidemic (China, 2020).

\section{References}

Brooks, S. K., Webster, R. K., Smith, L. E., Woodland, L., Wessely, S., Greenberg, N., \& Rubin, G. J. (2020). The psychological impact of quarantine and how to reduce it: a rapid review of the evidence. The Lancet.

China, N. H. C. o. (2020). Guidelines for psychological assistance hotlines during 2019-nCoV Pneumonia epidemic (in Chinese).

Folkman, S., \& Greer, S. (2000). Promoting psychological well-being in the face of serious illness: when theory, research and practice inform each other. Psycho-Oncology: Journal of the Psychological, Social and Behavioral Dimensions of Cancer, 9(1), 1119.

Gadit, A. A. M. (2007). Psychiatry in Pakistan: 1947-2006: A new balance sheet. JPMA, 57(9), 453-463.

Harley, S. J., \& Maunder, M. N. (2003). Recommended diagnostics for large statistical stock assessment models. Paper presented at the Sec. Pacific. Comm., Oceanic Fish. Prog. $16^{\text {th }}$ meeting, Stand. Comm. Tuna Billfish, MWG-3. Health, N. I. o. (2020). COVID19-NAP-V2-13-March-2020. From https://www.nih.org.pk/newsletters/

Husain, N., Chaudhry, I., Afridi, M., Tomenson, B., \& Creed, F. (2007). Life stress and depression in a tribal area of Pakistan. The British Journal of Psychiatry, 190(1), 3641.

Lima, C. K. T., de Medeiros Carvalho, P. M., Lima, I. d. A. S., de Oliveira Nunes, J. V. A., Saraiva,

J. S., de Souza, R. I., Neto, M. L. R. (2020). The emotional impact of Coronavirus 2019nCoV (new Coronavirus disease). Psychiatry Research, 112915.

Nickell, L. A., Crighton, E. J., Tracy, C. S., Al-Eazy, H., Bolaji, Y., Hanjrah, S., Upshur, R.E. (2004). Psychosocial effects of SARS on hospital staff: a survey of a large tertiary care institution. Cmaj, 170(5), 793-798.

PAHO. (2005). Protecting Mental Health During Epidemics. Retrieved 6 April 2020, from https://www.paho.org/en/file/21250/download?token=KJPzGOuM 
Pescosolido, B. A., \& Olafsdottir, S. (2013). Beyond dichotomies: confronting the complexity of how and why individuals come or do not come to mental health care. World Psychiatry, 12(3), 269.

Shah, I., Khalily, M. T., Ahmad, I., \& Hallahan, B., (2019). Impact of Conventional Beliefs and Social Stigma on Attitude Towards Access to Mental Health Services in Pakistan. Community mental health journal, 55(3), 527-533.

Sim, K., \& Chua, H. C. (2004). The psychological impact of SARS: a matter of heart and mind. Cmaj, 170(5), 811-812.

Thyloth, M., Singh, H., \& Subramanian, V. (2016). The increasing burden of mental illnesses across the globe: Current status. Indian Journal of Social Psychiatry, 32(3), 254.

Wang, C., Pan, R., Wan, X., Tan, Y., Xu, L., Ho, C. S., \& Ho, R. C. (2020). Immediate psychological responses and associated factors during the initial stage of the 2019 coronavirus disease (COVID-19) epidemic among the general population in China. International journal of environmental research and public health, 17(5), 1729.

Worldometer. (2020). Pakistan Coronavirus Cases. Retrieved 10 May 2020, from https://www.worldometers.info/coronavirus/country/pakistan/

Zhou, F., Yu, T., Du, R., Fan, G., Liu, Y., Liu, Z., Gu, X. (2020). Clinical course and risk factors for mortality of adult inpatients with COVID-19 in Wuhan, China: a retrospective cohort study. The Lancet. 